\title{
Evaluation of patients with multiple sclerosis using reverse nutech functional score and expanded disability status scale after human embryonic stem cell therapy
}

\author{
Geeta Shroff*
}

\begin{abstract}
Background: The expanded disability status scale (EDSS) is a validated and reliable tool to assess the extent of disabilities in patients with multiple sclerosis (MS). However, the use of this tool has been found to be limited in assessing various symptoms of MS that are important. Our study aimed at evaluating the efficacy of a new scoring system, reverse nutech functional score (RNFS) as compared to EDSS in assessing patients with MS treated with human embryonic stem cell (hESC) therapy.
\end{abstract}

Methods: The MS patients were treated with hESC therapy for one treatment period. All the patients were evaluated with EDSS and RNFS at baseline and after the hESC therapy.

Results: The study included a total of 24 MS patients with mean age of 45 year. The patients showed an improvement in parameters (sleeping disorders, paralysis, paraesthesia, myalgia, muscle weakness, memory, language, irritability, eye pain, depression and coordination, communication, breathing pattern, attention and appetite) associated with MS when evaluated with RNFS. This improvement went unnoticed when the patients were assessed with EDSS.

Conclusion: RNFS can efficiently assess the effectiveness of hESC therapy in treating patients with MS. It could be a suitable scoring system for patients with MS as it can assess the slightest improvements in the patients. Use in other settings would be helpful in assessing its utility.

Keywords: Multiple sclerosis, Reverse nutech functional score (RNFS), Human embryonic stem cell (hESC), Expanded disability status scale (EDSS)

\section{Background}

Multiple sclerosis (MS) is an autoimmune, chronic inflammatory demyelinating disease of the central nervous system (CNS) with genetic and environmental effects, among young and middle-aged adults $[1,2]$. It affects around 2.5 million people worldwide and is the third most common neurologic disorder cited as the cause of disability [3]. According to the Centers for Disease Control and Prevention (CDC), approximately $85 \%$ of the affected people have a relapsing-remitting course, characterized by an unpredictable course of

*Correspondence: geetashroff@hotmail.com

Nutech Mediworld, H-8, Green Park Extension, New Delhi 110016, India exacerbations and remissions [4]. The diagnosis of MS is based on the lesions present in the CNS which appears in the different areas of brain [5].

The rate of growth of the disease is extremely mutable and uncertain, with an unclear etiology. Presently there is no cure, and only symptomatic therapy is available. Generally, oral or intravenous corticosteroids like methylprednisolone is used at a high dose in the routine therapy for acute attacks which results in a faster recovery from the disability within a duration of three to five days of course [6]. However, the corticosteroid therapy does not have a significant impact on the long term disability [7]. The improvement in therapy is measured by means of expanded disability status scale (EDSS) [8]. 
Basically, EDSS quantifies disability in eight functional systems (FS) and allows neurologists to assign a functional systems scores (FSS) in each of these systems. It consists of ordinal rating system ranging from 0 (normal neurological status) to 10 (death due to MS) in 0.5 increments interval (when reaching EDSS 1) [8]. EDSS also has a number of limitations. It is dependent on mobility of patient. It is subjective in certain areas (e.g., bowel and bladder function). It is also insensitive to small changes. Further, it does not present an accurate picture of the patient's cognitive and functional abilities in performing activities of daily living (ADLs). It is nonlinear in terms of the time spent at various ranges of the scale [9].

We have previously published a case study of a patient with MS, who was treated with human embryonic stem cell therapy (hESC) and was assessed with EDSS before and after the therapy [10]. We have also developed a new functional, directional and positional scoring system, reverse nutech functional score (RNFS) to assess the patients with MS [11]. In the current study, we compared the two scoring systems, viz., RNFS and EDSS in patients with MS who underwent a single session of hESC therapy.

\section{Methods}

The RNFS scoring system assesses a symptom based on five ordinal grades that runs in a direction of GOOD $\rightarrow$ BAD. The RNFS system is also useful in conducting probability based studies as these scores have been converted into numeric values. It is a numeric scale that scores all the known symptoms for patients with MS. RNFS for MS is a 36-point positional (i.e., symptoms were sub-graded with a specific score) and directional (i.e., from level 1 to 5) scoring system that can be used to assess or validate the diagnosis of patients with MS [11] whereas EDSS is a scoring system which quantifies disability in eight FS. An improvement in the symptoms was determined on the basis of two criteria referred as W1 and $\mathrm{W} 2$, where $\mathrm{W} 1=$ number of cases by symptom that score < best possible grade (BPG) at the time of admission or at baseline (BL) and reached BPG at the end of therapy (ET); W2 = number of cases by symptom that scored differently later by at least one grade of RNFS/
EDSS as compared to the scores at $\mathrm{BL}$. W1 represented the positive effect of hESC therapy to cure MS whereas W2 exhibited the effect, whether negative, neutral or positive, on the condition of a MS patient.

The establishment and characterization of hESCs were explained in our previous paper [12]. All the patients were assessed for hypersensitivity reactions to hESC by subcutaneous (s.c.) injection of $0.25 \mathrm{~mL}$ hESCs. Subsequent to safety evaluation, hESCs were administered via intramuscular (i.m.) route (twice daily) to "prime" the body, $1 \mathrm{~mL}$ hESCs ( $<16$ million cells) were administered via intravenous (i.v.) route (twice every 7 days) to "home in" to the required area and 1-5 $\mathrm{mL}$ hESCs were administered via any of the supplemental routes including brachial plexus block, intrathecal, epidural catheter caudal, epidural and popliteal block and/or deep spinal muscle (every 7 days). All the patients received nasal sprays of $1 \mathrm{~mL}$ hESCs (3.5 million cells) twice a week to enhance the absorption of hESCs to the brain. The detailed methodology has been presented in Fig. 1. The safety studies of hESCs were explained in our previous paper [13].

In this study, the patients with MS were assessed with RNFS and EDSS. The RNFS/EDSS scores before and after the therapy were compared to assess which scoring system is better in evaluating the patients treated with hESC therapy. All the patients provided written informed consent prior to start of the study. The study was conducted in accordance with Declaration of Helsinki and approved by an independent Institutional Ethics Committee (IEC).

\section{Results}

Patients

A total of 24 patients with a mean age of 45 year were enrolled in the current study. The days of treatment in T1 varied from 42 to 84 days with a gap phase of 120-240 days.

\section{Patient wise status of EDSS grade at the ET}

Out of 24 patients, only one patient reached the BPG at ET and 21 patients showed change in grade after the treatment (Table 1).

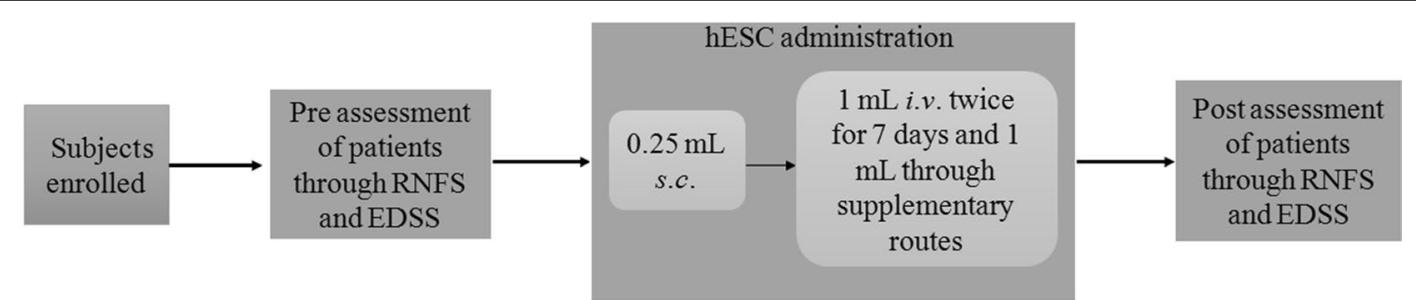

Fig. 1 Schematic diagram for methodology. RNFS reverse nutech functional score; EDSS expanded disability status scale; $h$ ESC human embryonic stem cell; sc subcutaneous; iv intravenous 
Table 1 Patient wise status of EDSS grade at the end of therapy

\begin{tabular}{|c|c|c|c|c|}
\hline Patient code & Age (years) & Gender & Reached BPG & $\begin{array}{l}\text { Change } \\
\text { in grade }\end{array}$ \\
\hline 80806 & 29 & $M$ & No & Yes \\
\hline 80926 & 35 & M & No & Yes \\
\hline 81128 & 64 & M & No & No \\
\hline 80680 & 61 & M & No & Yes \\
\hline 80710 & 43 & M & No & Yes \\
\hline 80488 & 32 & M & No & Yes \\
\hline 80499 & 61 & M & No & Yes \\
\hline 80723 & 25 & M & No & Yes \\
\hline 80981 & 56 & $\mathrm{~F}$ & Yes & Yes \\
\hline 80889 & 33 & $\mathrm{~F}$ & No & Yes \\
\hline 81238 & 30 & $F$ & No & Yes \\
\hline 81275 & 34 & F & No & Yes \\
\hline 81114 & 54 & $\mathrm{~F}$ & No & Yes \\
\hline 81249 & 45 & $\mathrm{~F}$ & No & Yes \\
\hline 81296 & 30 & $\mathrm{~F}$ & No & Yes \\
\hline 80568 & 53 & F & No & Yes \\
\hline 80626 & 54 & F & No & Yes \\
\hline 80562 & 47 & F & No & Yes \\
\hline 80768 & 57 & $\mathrm{~F}$ & No & Yes \\
\hline 81105 & 57 & $F$ & No & Yes \\
\hline 80673 & 32 & $\mathrm{~F}$ & No & Yes \\
\hline 80637 & 41 & $\mathrm{~F}$ & No & Yes \\
\hline 81187 & 53 & $F$ & No & No \\
\hline 81180 & 41 & $\mathrm{~F}$ & No & No \\
\hline
\end{tabular}

EDSS expanded disability status scale; $B P G$ best possible grade

\section{Cases that scored less than BPG at BL and reached BPG afterwards}

Number of affected parameters varied among the patients. Except five patients, all other patients showed an improvement (Table 2).

\section{Cases that scored differently later by at least one grade of RNFS}

All the patients scored differently by at least one grade. One of the patient had 22 parameters that scored $<$ BPG at $\mathrm{BL}$ and after the therapy, 20 (90.9\%) parameters improved by at least one grade Table 3 .

\section{Parameters that scored less than BPG at BL and reached BPG afterwards}

The scores for cases have also been categorized based on the affected parameters. Muscle weakness, an important symptom of MS, was scored to be as $<$ BPG in all the cases at BL. At ET, 3 (12.5 \%) patients reached BPG. Fatigue was scored as $<\mathrm{BPG}$ in 22 cases at BL, 8 (36.4 \%) of them
Table 2 Patient wise number of parameters that scored less than the best possible grade (<BPG) at baseline and reached BPG afterwards

\begin{tabular}{lll}
\hline Patient code & $\begin{array}{l}\text { Number of affected } \\
\text { parameters (<BPG) }\end{array}$ & $\begin{array}{l}\text { Parameters improved } \\
\text { at end of therapy; } \mathbf{n}(\%)\end{array}$ \\
\hline 80488 & 22 & $6(27.3)$ \\
80499 & 12 & $6(50.0)$ \\
80680 & 11 & 0 \\
80710 & 15 & $9(60.0)$ \\
80723 & 12 & $6(50.0)$ \\
80806 & 2 & $1(50.0)$ \\
80926 & 4 & 0 \\
81128 & 10 & $3(30.0)$ \\
80562 & 17 & $2(11.8)$ \\
80568 & 17 & $1(5.9)$ \\
80626 & 14 & $5(35.7)$ \\
80637 & 15 & $2(13.3)$ \\
80673 & 10 & $1(10.0)$ \\
80768 & 13 & $1(7.7)$ \\
80889 & 8 & $3(37.5)$ \\
80981 & 5 & $3(60.0)$ \\
81105 & 12 & $1(8.3)$ \\
81114 & 6 & 0 \\
81180 & 17 & $2(11.8)$ \\
81187 & 7 & 0 \\
81238 & 4 & $3(75.0)$ \\
81249 & 9 & $1(11.1)$ \\
81275 & 9 & $1(11.1)$ \\
81296 & 8 & 0 \\
\hline 896 & &
\end{tabular}

$B P G$ best possible grade

reached BPG at ET. The scores of all other parameters are presented in Table 4.

\section{Discussion}

In this study, an improvement in condition of the patients was evaluated more efficiently with RNFS system by highlighting even the slightest improvement. The levels in RNFS run in direction 1 (Good) $\rightarrow 5$ (Bad) and patients could be placed in these levels on the basis of their symptoms and functional limitations.

Gray and Butzkueven stated that EDSS is subjective in certain areas (e.g., bowel and bladder function). It is also insensitive to small changes. Further, it does not present an accurate picture of the patient's cognitive abilities and functional abilities in performing ADLs. It is nonlinear in terms of the time spent at various ranges of the scale [14]. Moreover, the practitioners and staff of our institute observed that EDSS emphasize mainly on the mobility of MS patients. The system is unable to assess other important parameters such as; sleeping disorders, paralysis, 
Table 3 Patient wise number of cases who scored differently later by at least one grade of RNFS score at baseline

\begin{tabular}{|c|c|c|c|}
\hline \multirow[t]{2}{*}{ patient code } & \multirow{2}{*}{$\begin{array}{l}\text { Number of affected } \\
\text { parameters at } B L \\
(<B P G)\end{array}$} & \multicolumn{2}{|c|}{$\begin{array}{l}\text { Alteration in score by at } \\
\text { least one grade }\end{array}$} \\
\hline & & $\begin{array}{l}\text { No change; } \\
\text { n (\%) }\end{array}$ & $\begin{array}{l}\text { Better; } \\
\text { n (\%) }\end{array}$ \\
\hline 80488 & 22 & $2(9.1)$ & $20(90.9)$ \\
\hline 80499 & 12 & $3(25.0)$ & $9(75.0)$ \\
\hline 80680 & 11 & 0 & $11(100.0)$ \\
\hline 80710 & 15 & $3(20.0)$ & $12(80.0)$ \\
\hline 80723 & 12 & $3(25.0)$ & $9(75.0)$ \\
\hline 80806 & 2 & $1(50.0)$ & $1(50.0)$ \\
\hline 80926 & 4 & $2(50.0)$ & $2(50.0)$ \\
\hline 81128 & 10 & $4(40.0)$ & $6(60.0)$ \\
\hline 80562 & 17 & 0 & $17(100.0)$ \\
\hline 80568 & 17 & $4(23.5)$ & $13(76.5)$ \\
\hline 80626 & 14 & $4(28.6)$ & $10(71.4)$ \\
\hline 80637 & 15 & $9(60.0)$ & $6(40.0)$ \\
\hline 80673 & 10 & $5(50.0)$ & $5(50.0)$ \\
\hline 80768 & 13 & $7(53.8)$ & $6(46.2)$ \\
\hline 80889 & 8 & $3(37.5)$ & $5(62.5)$ \\
\hline 80981 & 5 & 0 & $5(100.0)$ \\
\hline 81105 & 12 & $6(50.0)$ & $6(50.0)$ \\
\hline 81114 & 6 & $5(83.3)$ & $1(16.7)$ \\
\hline 81180 & 17 & $10(58.8)$ & $7(41.2)$ \\
\hline 81187 & 7 & $4(57.1)$ & $3(42.9)$ \\
\hline 81238 & 4 & 0 & $4(100.0)$ \\
\hline 81249 & 9 & $6(66.7)$ & $3(33.3)$ \\
\hline 81275 & 9 & $8(88.9)$ & $1(11.1)$ \\
\hline 81296 & 8 & $6(75.0)$ & $2(25.0)$ \\
\hline
\end{tabular}

RNFS reverse nutech functional score; $B L$ baseline; $B P G$ best possible grade

paraesthesia, myalgia, muscle weakness, memory, language, irritability, eye pain, depression, coordination, communication, breathing pattern, attention and appetite that were important to gauge in a patient with MS.

Schwid et al. reported in the study for comparing limitations of walking ability in MS patients, the EDSS and ambulation index (AI) were less sensitive to change than the $\mathrm{D} \max$ (the maximum distance that a person can go) and T8 (time to walk $8 \mathrm{~m}$ ) [15]. Similarly, Vaney et al. reported lesser changes in EDSS than in the Rivermead mobility index (RMI), the AI and the $10 \mathrm{~m}$ walking time test [16]. Hohol et al. reported a lower sensitivity to change in EDSS compared with disease steps [17]. Healy et al. conducted a study to assess the sustained disease progression in relapsing-remitting multiple sclerosis
Table 4 Parameter wise number of patients who scored less than the best possible grade (<BPG) at baseline and reached BPG afterwards

\begin{tabular}{|c|c|c|}
\hline Parameters & $\begin{array}{l}\text { Affected patients } \\
\text { (<BPG) }\end{array}$ & $\begin{array}{l}\text { Improved patients } \\
\text { at end of therapy; } \\
n(\%)\end{array}$ \\
\hline Appetite & 7 & $7(100.0)$ \\
\hline Attention & 3 & $3(100.0)$ \\
\hline $\begin{array}{l}\text { Balance-eyes closed } \\
\text { in straight line }\end{array}$ & 26 & $1(3.8)$ \\
\hline $\begin{array}{l}\text { Balance-eyes open in } \\
\text { straight line }\end{array}$ & 24 & $3(12.5)$ \\
\hline Bladder-control & 12 & $2(16.7)$ \\
\hline Bladder — sensation & 8 & $2(25.0)$ \\
\hline Bowel_control & 6 & $1(16.7)$ \\
\hline Bowel_-sensation & 4 & $2(50.0)$ \\
\hline $\begin{array}{l}\text { Breathing pattern- } \\
\text { Brady }\end{array}$ & 1 & $1(100.0)$ \\
\hline $\begin{array}{l}\text { Communication- } \\
\text { speech }\end{array}$ & 4 & $2(50.0)$ \\
\hline Coordination & 14 & 0 \\
\hline Deformity & 8 & $1(12.5)$ \\
\hline Depression & 6 & $4(66.7)$ \\
\hline $\begin{array}{l}\text { Double-vision + color } \\
\text { blindness }\end{array}$ & 5 & $1(20.0)$ \\
\hline Ears_hearing & 3 & $3(100.0)$ \\
\hline Eye pain & 2 & $2(100.0)$ \\
\hline Fatigue & 22 & $8(36.4)$ \\
\hline Floaters & 2 & $1(50.0)$ \\
\hline Irritability & 7 & $4(57.1)$ \\
\hline Language & 3 & $1(33.3)$ \\
\hline Limb tremors & 15 & $6(40.0)$ \\
\hline Memory & 7 & $5(71.4)$ \\
\hline Muscle weakness & 27 & $3(11.1)$ \\
\hline Myalgia & 11 & $5(45.5)$ \\
\hline Orientation-yes or no & 1 & $1(100.0)$ \\
\hline Pain & 18 & $7(38.9)$ \\
\hline Paralysis & 5 & 0 \\
\hline Paraesthesia & 11 & $5(45.5)$ \\
\hline Physical_drooling & 1 & $1(100.0)$ \\
\hline Sitting & 18 & $5(27.8)$ \\
\hline $\begin{array}{l}\text { Sleep disorder- } \\
\text { hypersomnia }\end{array}$ & 4 & $4(100.0)$ \\
\hline $\begin{array}{l}\text { Sleep disorder- } \\
\text { hyposomnia }\end{array}$ & 3 & $2(66.7)$ \\
\hline Stiffness & 19 & $10(52.6)$ \\
\hline Tingling & 7 & $3(42.9)$ \\
\hline Tinnitus & 3 & $3(100.0)$ \\
\hline Vision_-blurring & 11 & $3(27.3)$ \\
\hline
\end{tabular}

$B P G$ best possible grade 
(RRMS) with EDSS. The author found, between 15.8 and $42.2 \%$ of patients experienced sustained progression based on the definitions using EDSS as the outcome, but nearly $50 \%$ of these patients failed to maintain sustained progression for the duration of follow-up. The author concluded that short-term changes in the EDSS scores may not be an accurate marker of irreversible change in RRMS [18]. It has been difficult for clinicians to make normative evaluations of patient's motor potency with EDSS. However, RNFS system is a functional and parametric system that assesses a patient with MS on the basis of all the parameters that were associated with MS. In our study, RNFS identified even the smallest change in the parameters of MS. Figure 2 show the list of disease related parameters that are assessed by RNFS but not by EDSS.

Use of hESC therapy has generally led to a concern because of clinical non-viability in culturing of cells in a xeno-free environment. However, our institution uses a patented methodology [19] for the extraction, isolation and maintenance of hESCs $[12,13]$. The ability of stem cells to proliferate and to reconstruct the damaged parts offers excellent possibilities [20]. Previous studies have shown the potential of stem cells to migrate at the injury site and commence host repair and healing via the direct or indirect cell-signalling. In the course of brain injury, stem cells initiate neuroprotection and neural repair by inflammatory suppression, causing tissue reconstruction and avert cell damage. We have also reported the efficacy of hESCs in patients with MS [10]. The current study highlights the effectiveness of hESC therapy (as per the findings of RNFS and EDSS assessment) in the treatment of patients with MS. However, the assessment of MS lesions using gadolinium dye is warranted. Advances in this field are required to substantiate the efficacy results.

\section{Conclusion}

The RNFS is a solitary classification system for the patients of all ages with diminished complexity of the assessment system for the practitioners. So, we conclude that the newly developed RNFS is a unique tool can be used to gauge the betterment of patients receiving hESC therapy. Thus, this newly developed classification, functional and evaluation system can be used globally to help the patients with MS.
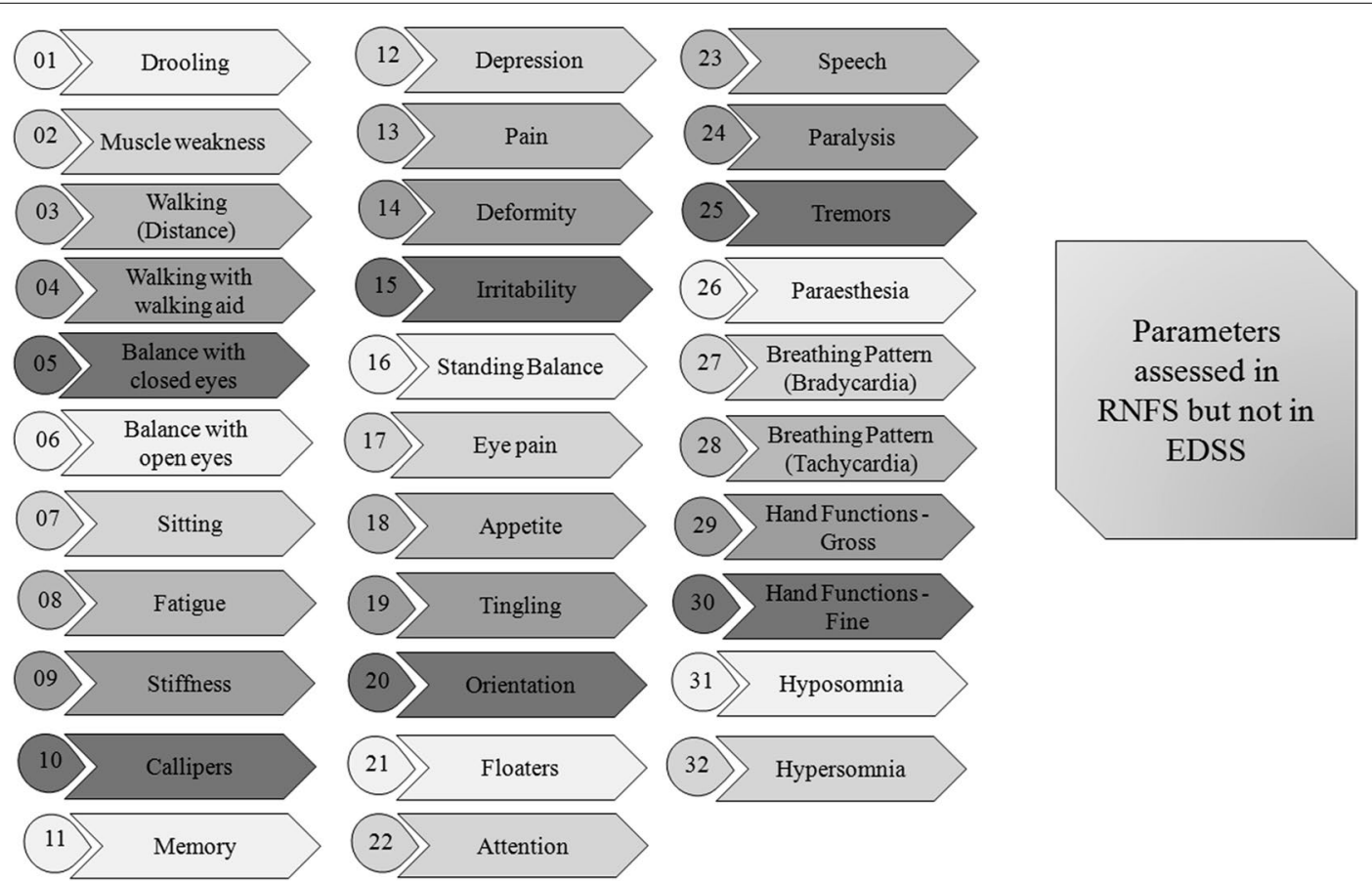

Fig. 2 Parameters covered by reverse nutech functional score but not by expanded disability status scale. RNFS reverse nutech functional score; EDSS expanded disability status scale 


\section{Abbreviations}

MS: multiple sclerosis; CNS: central nervous system; CDC: Centers of Disease Control and Prevention; EDSS: expanded disability status scale; FS: functional systems; FSS: functional systems scores; ADL: activities of daily living; hESC: human embryonic stem cell; RNFS: reverse nutech functional score; BPG: best possible grade; BL: baseline; ET: end of therapy; IEC: Institutional Ethics Committee; Al: ambulation index; RMI: Rivermead mobility index; RRMS: relapsingremitting multiple sclerosis.

\section{Acknowledgements}

The author acknowledges all the doctors, staff and patients of the Nutech Mediworld. The author also acknowledges Knowledge Isotopes Pvt. Ltd. (http://www.knowledgeisotopes.com) for the medical writing assistance.

\section{Competing interests}

The author declares that she has no competing interests.

\section{Ethics approval and consent to participate}

The study was conducted in accordance with Declaration of Helsinki and approved by an independent Institutional Ethics Committee (IEC). All the patients provided written informed consent prior to start of the study.

Received: 5 September 2016 Accepted: 5 October 2016

Published online: 20 October 2016

\section{References}

1. Wingerchuk DM, Carter $J$ (2014) Multiple sclerosis: current and emerging disease-modifying therapies and treatment strategies. Mayo Clin Proc 89(2):225-240

2. International Multiple Sclerosis Genetics Consortium, Wellcome Trust Case Control Consortium, Sawcer S, Hellenthal G, Pirinen M, Spencer CC et al (2011) Genetic risk and a primary role for cell-mediated immune mechanisms in multiple sclerosis. Nature 476(7359):214-219

3. Bethoux F, Bennett S (2011) Evaluating walking in patients with multiple sclerosis: which assessment tools are useful in clinical practice? Int J MS Care 13(1):4-14

4. Noonan CW, Williamson DM, Henry JP, Indian R, Lynch SG, Neuberger JS et al (2010) The prevalence of multiple sclerosis in 3 US communities. Prev Chronic Dis 7(1):A12

5. Calabresi PA (2004) Diagnosis and management of multiple sclerosis. Am Fam Physician 70(10):1935-1944

6. Sellebjerg F, Barnes D, Filippini G, Midgard R, Montalban X, Rieckmann P et al (2005) EFNS guideline on treatment of multiple sclerosis relapses: report of an EFNS task force on treatment of multiple sclerosis relapses. Eur J Neurol 12(12):939-946
7. Ciccone A, Beretta S, Brusaferri F, Galea I, Protti A, Spreafico C (2008) Corticosteroids for the long-term treatment in multiple sclerosis. Cochrane Database Syst Rev 1:CD006264

8. Kurtzke JF (1983) Rating neurologic impairment in multiple sclerosis: an expanded disability status scale (EDSS). Neurology 33(11):1444-1452

9. Sharrack B, Hughes RA, Soudain S, Dunn G (1999) The psychometric properties of clinical rating scales used in multiple sclerosis. Brain 122(Pt 1):141-159

10. Shroff G (2015) Human embryonic stem cell for the treatment of multiple sclerosis: a case report. Case Rep Int 4:38-42

11. Shroff G (2015) Scoring system approach of reverse Nutech functional score to assess patients with multiple sclerosis. J Neurol Transl Neurosci 4(2):1066

12. Shroff G (2015) Establishment and characterization of a neuronal cell line derived from a 2-cell stage human embryo: clinically tested cell-based therapy for neurological disorders. Int J Recent Sci Res 6(4):3730-3738

13. Shroff G, Barthakur JK (2015) Safety of human embryonic stem cells in patients with terminal/incurable conditions - a retrospective analysis. Ann Neurosci 22(3):132-138

14. Gray O, Butzkueven $\mathrm{H}$ (2008) Measurement of disability in multiple sclerosis. Neurol Asia 13:153-156

15. Schwid SR, Goodman AD, Apatoff BR, Coyle PK, Jacobs LD, Krupp LB et al (2000) Are quantitative functional measures more sensitive to worsening MS than traditional measures? Neurology 55(12):1901-1903

16. Vaney C, Blaurock H, Gattlen B, Meisels C (1996) Assessing mobility in multiple sclerosis using the Rivermead mobility index and gait speed. Clin Rehabil 10(3):216-226

17. Hohol MJ, Orav EJ, Weiner HL (1995) Disease steps in multiple sclerosis: a simple approach to evaluate disease progression. Neurology 45(2):251-255

18. Healy BC, Engler D, Glanz B, Musallam A, Chitnis T (2013) Assessment of definitions of sustained disease progression in relapsing-remitting multiple sclerosis. Mult Scler Int 2013:189624

19. World Intellectual Property Organization. 21. (WO2007141657) Compositions comprising human embryonic stem cells and their derivatives, methods of use, and methods of preparation. https://www.patentscope. wipo.int/search/en/detail.jsf?docld=WO2007141657\&recNum=21\&max Rec $=21 \&$ office $=$ \&prevFilter $=$ \&sortOption $=$ Pub+Date+Desc\&queryStrin $g=F P \% 3 A$ (geeta+shroff)\&tab=PCTDescription. Accessed 20 Aug 2016

20. UI Hassan A, Hassan G, Rasool Z (2009) Role of stem cells in treatment of neurological disorder. Int J Health Sci (Qassim) 3(2):227-233

\section{Submit your manuscript to a SpringerOpen ${ }^{\circ}$ journal and benefit from:}

- Convenient online submission

- Rigorous peer review

- Immediate publication on acceptance

- Open access: articles freely available online

- High visibility within the field

- Retaining the copyright to your article 